\title{
ANALISIS FAKTOR KOMPENSASI DAN MOTIVASI KERJA TERHADAP KINERJA KARYAWAN PUSAT PENELITIAN KELAPA SAWIT (PPKS) KEBUN BUKIT SENTANG DESA SECURAI KECAMATAN BABALAN KABUPATEN LANGKAT
}

\author{
Muhammad Rizqi Zati ${ }^{1{ }^{*}}$, Abdul Latief ${ }^{2)}$, Siti Mariana ${ }^{3)}$ \\ 1) Fakultas Ekonomi, Universitas Samudra \\ Email: Rizqi_Zati@unsam.ac.id \\ 2) Fakultas Ekonomi, Universitas Samudra \\ Email: Latief@unsam.ac.id \\ 3) Fakultas Ekonomi, Universitas Samudra \\ Email: msiti2549@gmail.com
}

\begin{abstract}
Abstrak
Penelitian ini bertujuan untuk mengetahui pengaruh kompensasi dan motivasi kerja terhadap kinerja karyawan pada Pusat Penelitian Kelapa Sawit (PPKS) kebun bukit sentang desa securai kecamatan babalan kabupaten langkat. Penelitian ini merupakan jenis penelitian kuantitatif dengan metode pengambilan sampel adalah teknik nonprobability sampling dengan sampling jenuh dan ditetapkan jumlah sampel sebanyak 47 responden. Uji hipotesis yang dilakukan melalui uji parsial (uji t), uji simultan (uji F), dan uji koefisien determinasi (R2). Dari analisis data diperoleh persamaan regresi $\mathrm{Y}=$ $2,840+0,106 \mathrm{X} 1+0,262 \mathrm{X} 2$. Secara parsial (melalui analisis uji t) kedua varibel bebas yaitu kompensasi $(0,514)$ dan motivasi kerja $(0,113)$ tidak ada yang berpengaruh secara signifikan terhadap kinerja karyawan. Sedangkan secara simultan (melalui uji F) kedua variabel bebas yaitu kompensasi dan motivasi kerja $(0,113)$ berpengaruh secara positif dan tidak signifikan terhadap kinerja karyawan pada Pusat Penelitian Kelapa Sawit (PPKS) kebun bukit sentang desa securai kecamatan babalan kabupaten langkat. Dari hasil koefisien determinasi (R2) diketahui bahwa variabel kompensasi dan motivasi kerja mempengaruhi kinerja karyawan pada Pusat Penelitian Kelapa Sawit (PPKS) kebun bukit sentang desa securai kecamatan babalan kabupaten langkat sebesar 9,4\%, dan sisanya sebesar 90,6\% dipengaruhi oleh variabel lain seperti pengetahuan, teknis, ketergantungan terhadap orang lain, kebijakan, kemampuan karyawan, kehadiran, kepemimpinan, dan minat.
\end{abstract}

Keywords: Kompensasi, Motivasi Kerja, Kinerja Karyawan 


\section{PENDAHULUAN}

Setiap organisasi memiliki tujuan yang ingin dicapai. Dalam mencapai tujuan tersebut, peranan sumber daya manusia dalam hal ini karyawan yang ada di dalamnya sangatlah penting. Secara umum, karyawan yang ada didalam suatu organisasi/perusahaan mengharapkan peningkatan kesejahteraan. Untuk menggerakkan sumber daya manusia yang ada agar berjalan sesuai dengan yang dikehendaki organisasi, maka sangatlah penting memahami motivasi manusia yang bekerja di dalam organisasi tersebut, karena motivasi inilah yang mengerakan perilaku orang-orang untuk bekerja, atau dengan kata lain perilaku merupakan cerminan yang paling sederhana dari motivasi. Hasibuan (2010) mengatakan bahwa motivasi kerja merupakan hal yang sulit dilakukan karena perusahaan tidak mengetahui secara pasti apa kebutuhan dan keinginan dari karyawan. Menurut Asep dan Tanjung (2004) adapun motivasi kerja dapat diukur dari tingkat absensi, kedisiplinan, serta kerja sama yang terjadi antar karyawan.

Dalam hal ini jika motivasi kerja tinggi maka tingkat kedisiplinan dan kehadiran akan baik, tentu saja ini mempengaruhi kinerja mereka dalam bekerja, Menurut Sutrisno (2015) faktor yang mempengaruhi motivasi kerja karyawan adalah salah satunya kompensasi yang memadai. Kompensasi sangat penting bagi karyawan itu sendiri sebagai individu, karena besarnya kompensasi merupakan pencerminan atau ukuran nilai pekerjaan karyawan itu sendiri. Apabila kompensasi diberikan secara tepat dan benar, maka dapat meningkatkan kinerja dan menumbuhkan motivasi dalam diri karyawan untuk membantu perusahaan dalam mencapai tujuan.

Permasalah umum yang dirasakan oleh karyawan adalah masalah yang berkaitan dengan kompensasi, seperti masalah pemberian bonus yang sudah jarang diterima dan keterlambatan pemberian gaji setiap pertengahan bulan. Pusat Penelitian Kelapa Sawit (PPKS) kebun bukit sentang desa securai kecamatan babalan kabupaten langkat memiliki kebijakan memberikan gaji kepada karyawannya sebanyak dua kali dalam satu bulan, yaitu pada pertengahan bulan dan akhir bulan. Perhatian perusahaan terhadap motivasi kerja karyawan dan kompensasi yang diberikan perlu diperhatikan oleh perusahaan agar kinerja karyawan dapat meningkat dan semakin baik.

\section{TINJAUAN PUSTAKA}

\section{Kompensasi}

Menurut Sutrisno (2015:187), kompensasi adalah semua jenis penghargaan yang berupa uang atau bukan uang yang diberikan kepada karyawan secara layak dan adil atas jasa mereka dalam mencapai tujuan perusahaan. Menurut Hasibuan (2012:118), kompensasi adalah semua pendapatan yang berbentuk uang, barang langsung atau tidak langsung yang diterima karyawan sebagai imbalan atas jasa yang diberikan kepada perusahaan.

Faktor yang mempengaruhi Kompensasi

1. Penawaran dan Permintaan Tenaga Kerja

2. Kemampuan dan Kesediaan Perusahaan

3. Serikat Buruh/organisasi Karyawan

4. Produktivitas Kerja Karyawan

5. Pemerintah dengan Undang-Undang dan Keppres

6. Biaya Hidup/Cost of Living

7. Posisi Jabatan Karyawan

8. Pendidikan dan Pengalaman Kerja

9. Kondisi Perekonomian Nasional

10. Jenis dan Sifat Pekerjaan

\section{Motivasi Kerja}


Menurut Wilson (2012:312), mengatakan bahwa motivasi adalah suatu kondisi yang mendorong orang lain untuk dapat melaksanakan tugas-tugas sesuai dengan fungsinya dalam organisasi. Menurut Sutrisno (2015:111), motivasi adalah suatu faktor yang mendorong seseorang untuk melakukan suatu aktivitas tertentu, oleh karena itu motivasi sering kali diartikan pula sebagai faktor pendorong perilaku seseorang.

\section{Faktor-faktor yang Mempengaruhi Motivasi Kerja}

Menurut Sutrisno (2015:116) faktor-faktor itu dapat dibedakan atas faktor intern dan ekstern yang berasal dari karyawan. Adapun faktor tersebut sebagai berikut:

1. Faktor Intern

a. Keinginan untuk dapat hidup

b. Keinginan untuk dapat memiliki

c. Keinginan untuk memperoleh penghargaan

d. Keinginan untuk memperoleh pengakuan

e. Keinginan untuk berkuasa

2. Faktor Ekstern

a. Kondisi lingkungan kerja

b. Kompensasi yang memadai

c. Supervisi yang baik

d. Adanya jaminan pekerjaan

e. Status dan tanggung jawab

f. Peraturan yang fleksibel

Indikator Motivasi Kerja

Menurut Maslow dalam Sunyoto (2015:194), bahwa motivasi dipengaruhi oleh beberapa faktor yang digunakan sebagai indikator-indikator untuk mengetahui tingkat motivasi karyawan, yaitu sebagai berikut:

1. Kebutuhan Fisiologi (physiological needs

2. Kebutuhan Rasa Aman (safety needs)

3. Kebutuhan Sosial (social needs)

4. Kebutuhan Penghargaan (esteem needs)
5. Kebutuhan aktualitas diri (self actualization needs)

\section{Kinerja}

Menurut Wilson (2012:231), kinerja (performance) adalah hasil pekerjaan yang dicapai seseorang berdasarkan persyaratan-persyaratan pekerjaan (job requirement). Fahmi (2015:02), kinerja adalah hasil kerja yang diperoleh oleh suatu organisasi baik itu organisasi tersebut bersifat profit oriented dan non profit oriented.

Faktor-faktor yang Mempengaruhi Kinerja

Menurut Prawirosntono (dalam Damayanti at all.:2013), faktor-faktor yang mempengaruhi kinerja adalah: Pengetahuan, teknis, ketergantungan terhadap orang lain, kebijakan, kemampuan karyawan, kehadiran, kepemimpinan, dan minat.

Indikator Kinerja

Menurut Siamora (dalam Wijaya dan Andreani (2015:40), ada tiga indikator untuk menilai kompensasi. Adapun indikator tersebut yaitu:

1. Puas terhadap gaji

2. Puas terhadap fasilitas

3. Puas terhadap tunjangan.

\section{METODE PENELITIAN Jenis Penelitian}

Jenis penelitian ini adalah penelitian kuantitatif. Data yang diperoleh diolah menggunakan program SPSS for Windows versi 20.

\section{Populasi Dan Sampel}

Populasi dalam penelitian ini adalah seluruh karyawan yang ada pada Pusat Penelitian Kelapa Sawit (PPKS) Kebun Bukit Sentang Desa Securai Kecamatan Babalan Kabupaten Langkat yang berjumlah 47 orang. Jumlah sampel dalam penelitian ini 47 responden di mana seluruh populasi dijadikan sampel penelitian. 


\section{Teknik Pengambilan Data}

Untuk memperoleh data yang dibutuhkan guna mendukung penelitian ini, metode pengumpulan data yang diguakan dalam penelitian ini adalah sebagai berikut :

a. Penelitian Lapangan (Field Research)

Penelitian lapangan merupakan penelitian yang dilakukan dengan mengumpulkan data dan informasi yang diperoleh langsung dari responden dan mengamati secara langsung kinerja karyawan pada Pusat Penelitian Kelapa Sawit (PPKS) Kebun Bukit Sentang Desa Securai Kecamatan Babalan Kabupaten Langkat. Dalam hal penelitian ini peneliti memperoleh data dengan beberapa cara, yaitu:

1. Observasi (Pengamatan), Merupakan pengamatan yang dilakukan dengan mengumpulkan data yang diperoleh secara langsung dan observasi tidak terbatas pada orang, tetapi objekobjek lainnya yang ada dari Pusat Penelitian Kelapa Sawit (PPKS) Kebun Bukit Sentang Desa Securai Kecamatan Babalan Kabupaten Langkat,

2. Interview (Wawancara), Dalam hal ini peneliti melakukan wawancara dengan pihak-pihak yang berhubungan dengan penelitian ini yaitu pimpinan dan staf bagian tata usaha dan karyawan yang kebetulan berada di tempat.

3. Kuestioner (Angket), Merupakan teknik pengumpulan data dengan memberikan daftar pertanyaan untuk dijawab secara tulisan oleh karyawan. Dengan melakukan penyebaran kuestioner kepada responden, untuk mengukur persepsi responden digunakan Skala Likert..

HASIL DAN PEMBAHASAN

Tabel 1

Coefficients $^{\mathrm{a}}$

\begin{tabular}{|c|c|c|c|c|c|}
\hline \multirow[t]{2}{*}{ Model } & \multicolumn{2}{|c|}{$\begin{array}{l}\text { Unstandardized } \\
\text { Coefficients }\end{array}$} & \multirow{2}{*}{$\begin{array}{c}\begin{array}{c}\text { Standardized } \\
\text { Coefficients }\end{array} \\
\text { Beta }\end{array}$} & \multirow[t]{2}{*}{$\mathrm{t}$} & \multirow[t]{2}{*}{ Sig. } \\
\hline & B & Std. Error & & & \\
\hline (Constant) & 2.840 & .713 & & 3.985 & .000 \\
\hline 1 Kompensasi & .106 & .161 & .103 & .658 & .514 \\
\hline Motivasi Kerja & .262 & .162 & .252 & 1.617 & .113 \\
\hline
\end{tabular}

a. Dependent Variable: Kinerja

b. Sumber: Hasil Pengolahan SPSS (2018)

Pada Tabel 1, berdasarkan nilai Unstandardized Coefficients (B) didapat persamaan regresi linier berganda untuk penelitian ini adalah sebagai berikut:

$Y=2,840+0,106 X_{1}+0,262 X_{2}$
Dari persamaan regresi linier berganda tersebut, maka dapat diinterprestasikan bahwa:

1. Nilai konstanta memiliki nilai yang positif sebesar 2,840, hal ini berarti bahwa jika nilai variabel kompensasi dan motivasi kerja dianggap tetap dan bernilai nol, maka kinerja karyawan masih memiliki 
nilai positif. Hasil persamaan regresi menunjukkan bahwa kedua variabel bebas yaitu, kompensasi dan motivasi berpengaruh secara positif terhadap variabel terikat yaitu kinerja karyawan. Hal ini menunjukan bahwa kinerja karyawan akan baik ataupun tinggi jika motivasi kerja dan kompensasi yang diberikan oleh perusahaan sesuai dengan harapan mereka.

2. Nilai unstandardized coefficients (B) untuk variabel X1 (kompensasi) yang bernilai positif sebesar 0,106 menunjukkan bahwa terdapat pengaruh positif antara variabel kompensasi dengan kinerja karyawan. Jadi jika variabel kompensasi meningkat maka kinerja karyawan pada Pusat Penelitian Kelapa Sawit (PPKS) kebun bukit sentang desa
NIAGAWAN Vol 7 No 2 Juli 2018

securai kecamatan babalan kabupaten langkat akan semakin meningkat.

3. Nilai unstandardized coefficients (B) untuk variabel X2 (Motivasi kerja) yang bernilai positif sebesar 0,262 menunjukkan bahwa terda pat pengaruh positif antara variabel motivasi kerja dengan keputusan investasi. Jadi jika variabel motivasi kerja meningkat maka kinerja karyawan pada Pusat Penelitian Kelapa Sawit (PPKS) kebun bukit sentang desa securai kecamatan babalan kabupaten langkat juga akan semakin meningkat.

\section{Hasil Uji t}

Hasil uji $\mathrm{t}$ atau uji signifikansi variabel kompensasi dan motivasi kerja secara parsial terhadap kinerja karyawan dapat diketahui dengan melihat tabel IV-2, dengan penjelasan sebagai berikut:

\section{Tabel 2}

Coefficients $^{\mathrm{a}}$

\begin{tabular}{|c|c|c|c|c|c|}
\hline \multirow[t]{2}{*}{ Model } & \multicolumn{2}{|c|}{$\begin{array}{c}\text { Unstandardized } \\
\text { Coefficients }\end{array}$} & \multirow{2}{*}{$\begin{array}{c}\begin{array}{c}\text { Standardized } \\
\text { Coefficients }\end{array} \\
\text { Beta }\end{array}$} & \multirow[t]{2}{*}{$\mathrm{t}$} & \multirow[t]{2}{*}{ Sig. } \\
\hline & B & Std. Error & & & \\
\hline (Constant) & 2.840 & .713 & & 3.985 & .000 \\
\hline 1 Kompensasi & .106 & .161 & .103 & .658 & .514 \\
\hline Motivasi Kerja & .262 & .162 & .252 & 1.617 & 113 \\
\hline
\end{tabular}

Sumber: Hasil Penelitian 2018

a. Variabel kompensasi (X1) memiliki thitung sebesar 0,658 dan $t_{\text {tabel }}$ pada probibalitas 0,05 adalah sebesar 0,680 . Oleh karena $\mathrm{t}_{\text {hitung }}<\mathrm{t}_{\text {tabel }}$ atau $0,658<1,680$ dan nilai $\mathrm{t}$ sig sebesar 0,514. Karena nilai $\mathrm{t}$ sig > $(0,05)$ berarti variabel kompensasi mempunyai pengaruh parsial yang tidak signifikan terhadap kinerja karyawan pada Pusat Penelitian Kelapa Sawit (PPKS) kebun bukit sentang desa securai kecamatan babalan kabupaten langkat.

b. Variabel motivasi kerja (X2) memiliki $t_{\text {hitung }}$ sebesar 1,617 dan $t_{\text {tabel }}$ pada probibalitas 0,05 adalah sebesar 1,680. Oleh karena $t_{\text {hitung }}>t_{\text {tabel }}$ atau 1,617 > 0,680 dan nilai t sig sebesar 0,113 . Karena nilai $\mathrm{t}$ sig $>(0,05)$ berarti variabel kompensasi mempunyai pengaruh parsial yang tidak signifikan terhadap kinerja karyawan pada Pusat Penelitian Kelapa Sawit (PPKS) kebun bukit sentang desa securai kecamatan babalan kabupaten langkat.

Berdasarkan uraian hasil tersebut maka tampak bahwa tidak ada variabel yang memiliki pengaruh secara parsial yang signifikan terhadap kinerja karyawan pada Pusat Penelitian Kelapa Sawit (PPKS) Kebun Bukit Sentang desa securai kecamatan babalan kabupaten langkat. Dengan demikian, $\mathrm{H}_{0}$ diterima dan $\mathrm{H}_{\mathrm{a}}$ ditolak atau tidak terbukti kebenarannya. 
p-ISSN : 2301-7775

e-ISSN : 2579-8014

NIAGAWAN Vol 7 No 2 Juli 2018

2. Hasil Uji F

Hasil uji $F$ variabel kompensasi dan motivasi kerja secara simultan terhadap kinerja karyawan dapat dilihat pada tabel 3 berikut

Tabel 3

ANOVAa

\begin{tabular}{|l|l|l|l|l|l|}
\hline Model & Sum of Squares & Df & Mean Square & F & Sig. \\
\hline \multicolumn{1}{|c|}{ Regression } & 1.307 & 2 & .653 & 2.296 & $.113^{\mathrm{b}}$ \\
1 Residual & 12.523 & 44 & .285 & & \\
$\quad$ Total & 13.830 & 46 & & & \\
\hline
\end{tabular}

Sumber: Hasil Penelitian 2018 
Berdasarkan hasil analisis tampak bahwa model penelitian ini memiliki $F_{\text {hitung }}$ sebesar 2,296 dengan $F$ sig sebesar 0,113. Sedangkan $\mathrm{F}_{\text {tabel }}$ pada tingkat kepercayaan $95 \%$ $(\alpha=0,05)$ adalah 2,82. Karena nilai sig $F$ sebesar $0,113>(0,05)$ sehingga dapat dinyatakan bahwa variabel-variabel independen yang meliputi kompensasi (X1) motivasi kerja (X2), mempunyai pengaruh simultan yang tidak signifikan terhadap kinerja karyawan pada Pusat Penelitian Kelapa Sawit (PPKS) Kebun Bukit Sentang desa securai kecamatan kabupaten langkat. Dengan demikian, $\mathrm{H}_{0}$ diterima dan $\mathrm{H}_{\mathrm{a}}$ ditolak atau tidak terbukti kebenarannya.

\section{Hasil Uji Koefisien Determinasi}

Tabel 4

Model Summary

\begin{tabular}{|l|l|l|}
\hline Model & R & R Square \\
\hline 1 & $.307^{\mathrm{a}}$ & .094 \\
\hline
\end{tabular}

a. Predictors: (Constant), Motivasi Kerja, Kompensasi

Sumber: Hasil pengolahan SPSS (2018)

Dari hasil pada Tabel 4 tampak bahwa nilai $R$ Square sebesar 0,094. Interprestasinya adalah bahwa variabel-variabel independen yang digunakan dalam model penelitian ini memberi kontribusi sebesar 9,4\% untuk menjelaskan pengaruh variabel-variabel terhadap kinerja karyawan pada Pusat Penelitian Kelapa Sawit (PPKS) Kebun Bukit Sentang desa securai kecamatan babalan kabupaten langkat. Sedangkan sisanya sebesar 90,6\% (100\% $9,4 \%$ ) dijelaskan oleh variabel Pengetahuan, teknis, ketergantungan terhadap orang lain, kebijakan, kemampuan karyawan, kehadiran, kepemimpinan, dan minat.

\section{KESIMPULAN DAN SARAN}

Berdasarkan hasil penelitian mengenai pengaruh variabel kompensasi dan motivasi kerja terhadap kinerja karyawan pada Pusat Penelitian Kelapa Sawit (PPKS) Kebun Bukit Sentang Desa Securai Kecamatan Babalan Kabupaten Langkat, bahwa variabel kompensasi mempunyai pengaruh yang cukup besar, karena kompensasi merupakan salah satu alasan mengapa karyawan mau bekerja. Pemberian kompensasi ditentukan oleh beban kerja serta pengorbanan yang diberikan karyawan. Jika perusahaan memberikan kompensasi setara dengan pengorbanan yang dikeluarkan maka tidak akan menimbulkan ketidakpuasan karyawan yang pada akhirnya akan menurunkan kinerja karyawan tersebut. Jadi jika variabel kompensasi meningkat maka kinerja karyawan pada Pusat Penelitian Kelapa Sawit (PPKS) Kebun Bukit Sentang Desa Securai Kecamatan Babalan Kabupaten Langkat akan semakin meningkat.

Variabel motivasi kerja berpengaruh secara positif namun tidak signifikan. Nilai variabel motivasi kerja sangat besar dibandingkan dengan kompensasi karena motivasi kerja adalah dorongan dalam diri karyawan agar rela dan bersedia mengeluarkan segala kemampuan dan tenaga untuk membantu perusahaan mewujudkan tujuannya. Jika pemberian motivasi kerja ditingkatkan, salah satunya adalah dengan memberikan kompensasi dalam bentuk finansisal maupun non finansial maka secara langsung karyawan akan bersemangat dalam bekerja dan merasa dianggap sebagai salah satu bagian perusahaan, sebagai timbal balik karyawan akan berusaha meningkatkan kinerjanya. Namun sebaliknya jika pemberian motivasi kerja menurun atau bahkan tidak diperdulikan, maka perusahaan akan menanggung akibatnya karena kinerja karyawan menurun. Jadi jika variabel motivasi kerja meningkat maka kinerja karyawan pada Pusat Penelitian Kelapa Sawit (PPKS) Kebun Bukit Sentang Desa Securai Kecamatan Babalan Kabupaten Langkat juga akan semakin meningkat. Hal ini menunjukan bahwa kinerja karyawan akan baik ataupun tinggi jika kompensasi dan motivasi kerja yang diberikan oleh perusahaan sesuai dengan harapan mereka. Pusat Penelitian Kelapa Sawit (PPKS) Kebun Bukit Sentang Desa Securai Kecamatan Babalan Kabupaten Langkat diharapkan memperhatikan pemberian kompensasi kepada karyawan dan memperhatikan motivasi kerja karyawan hal ini dikarenakan Kompensasi dan Motivasi Kerja berpengaruh terhadapa kinerja karyawan. Selanjutnya untuk peneliti lain yang akan meneliti permasalahan yang sejenis, diharapkan memperhatikan jumlah sampel yang lebih besar agar data yang diperoleh lebih maksimal.

\section{REFERENSI}

Asep \& Tanjung, 2004, Pengembangan Sumber Daya Manusia, Jakarta: Universitas Trisakti.

Bangun, Wilson. 2012. Manajemen Sumber Saya Manusia. Bandung: Erlangga 
Damayanti, Agiel Puji; Susilaningsih;

Sumaryati, Sri. Pengaruh Kompensasi

Dan Motivasi Kerja Terhadap Kinerja

Karyawan Perusahaan Daerah Air Minum

(PDAM) Surakarta. Jurnal Pendidikan

Ekonomi Universitas Sebelas Maret.Vol.

2, No 1, hal 155 - 168.

Fahmi, Irham. 2010, Manajemen Kinerja, Alfabeta: Bandung.

Hasibuan, 2010, PT BHP Biliton Indonesia:

Kompensasi Tidak Menjamin Karyawan

Akan Loyal, Organisasi dan motivasi

kerja, Diakses 18 Februari 2018,

$<$ http://portalhr.com/people-

management/employeerelations/pt-bhp-

biliton-indonesia-kompensasi-tidak-

menjamin-karyawan-akan-loyal>.

Hasibuan, Malayu S.P. 2012. Manajemen

Sumber Daya Manusia. Jakarta: Bumi

Aksara

Prakoso, Medi. 2016. Pengaruh Motivasi Kerja

Dan Kompensasi Terhadap Kinerja

Karyawan Percetakan Art Studio Jakarta

Pusat. Skripsi. Yogyakarta. Prodi Manajemen.

Sugiyono, 2011. Metode Penelitian Kuantitatif Kualitatif dan R\&D, Bandung : Alfabeta.

Sugiyono, 2011. Statistika Untuk Penelitian, Bandung: Alfabeta.

Sunyoto, Danang. 2014. Manajemen Dan Pengembangan Sumber Daya Manusia. Yogyakarta: PT Buku Seru.

Sutrisno, H. Edy. 2015. Manajemen Sumber Daya Manusia, Jakarta : Kencana.

Wijaya, Tanto dan Adreani, Fransisca. 2015. Pengaruh Motivasi Dan Kompensasi Terhadap Kinerja Karyawan Pada PT. Sinar Jaya Abadi Bersama. Agora Jurnal Manajemen Bisnis. Vol.3, No.2, hal 3745.

Yuli Suwati, 2013, Pengaruh Kompensasi Dan motivasi Kerja Terhadap Kinerja Karyawan Pada PT. Tunas Hijau Samarinda, Jurnal Ilmu Administrasi Bisnis. Vol 1, No 1, 2013, hal 41 - 55.

Yuniarsih, Tjutju dan Suwatno. 2014. Manajemen Sumber Daya Manusia. Bandung : Alfabeta.

Zamani, P Oktav. 2011. Pedoman Hubungan Industrial. Jakarta: PPM 